Article

\title{
Innovative Low-Cost Carbon/ZnO Hybrid Materials with Enhanced Photocatalytic Activity towards Organic Pollutant Dyes' Removal
}

\author{
Petronela Pascariu $^{1,2, *}$, Niculae Olaru ${ }^{1}$, Aurelian Rotaru ${ }^{2}(1)$ and Anton Airinei ${ }^{1}$ \\ 1 "Petru Poni" Institute of Macromolecular Chemistry, 41A Grigore Ghica Voda Alley, 700487 Iasi, Romania; \\ nolaru@icmpp.ro (N.O.); airineia@icmpp.ro (A.A.) \\ 2 Faculty of Electrical Engineering and Computer Science \& MANSiD Research Center, \\ Stefan cel Mare University, 13 Str. Universitatii, 720229 Suceava, Romania; aurelian.rotaru@usm.ro \\ * Correspondence: dorneanu.petronela@icmpp.ro or pascariu_petronela@yahoo.com
}

Received: 10 August 2020; Accepted: 15 September 2020; Published: 18 September 2020

\begin{abstract}
A new type of material based on carbon/ZnO nanostructures that possesses both adsorption and photocatalytic properties was obtained in three stages: cellulose acetate butyrate (CAB) microfiber mats prepared by the electrospinning method, $\mathrm{ZnO}$ nanostructures growth by dipping and hydrothermal methods, and finally thermal calcination at $600{ }^{\circ} \mathrm{C}$ in $\mathrm{N}_{2}$ for $30 \mathrm{~min}$. X-ray diffraction (XRD) confirmed the structural characteristics. It was found that $\mathrm{ZnO}$ possesses a hexagonal wurtzite crystalline structure. The $\mathrm{ZnO}$ nanocrystals with star-like and nanorod shapes were evidenced by scanning electron microscopy (SEM) measurements. A significant decrease in $E_{\mathrm{g}}$ value was found for carbon/ZnO hybrid materials $(2.51 \mathrm{eV})$ as compared to $\mathrm{ZnO}$ nanostructures $(3.21 \mathrm{eV})$. The photocatalytic activity was evaluated by studying the degradation of three dyes, Methylene Blue (MB), Rhodamine B (RhB) and Congo Red (CR) under visible-light irradiation. Therefore, the maximum color removal efficiency (both adsorption and photocatalytic processes) was: $97.97 \%$ of $\mathrm{MB}\left(C_{0}=10 \mathrm{mg} / \mathrm{L}\right), 98.34 \%$ of $\mathrm{RhB}\left(C_{0}=5 \mathrm{mg} / \mathrm{L}\right)$, and $91.93 \%$ of $\mathrm{CR}\left(C_{0}=10 \mathrm{mg} / \mathrm{L}\right)$. Moreover, the value of the rate constant $(k)$ was found to be $0.29 \times 10^{-2} \mathrm{~min}^{-1}$. The novelty of this study relies on obtaining new photocatalysts based on carbon/ZnO using cheap and accessible raw materials, and low-cost preparation techniques.
\end{abstract}

Keywords: carbon/ZnO nanostructures; electrospinning; photocatalyst; photocatalytic activity

\section{Introduction}

A major worldwide problem of modern society is the disposal and treatment of wastewater coming from industrial processes. It is known that about $97 \%$ of water is represented by oceans in the form of salty water. This is not appropriate for human consumption or agricultural use, and only less than $3 \%$ of water is useful [1]. The quality and quantity of water are the main issues that need to be addressed by finding methods to eliminate contaminants or pollutants 195 induce adverse environmental effects, as well as for human health. In addition, the residual liquids containing dyes coming from the textile industry often create severe environmental hazards because of their direct disposal into nearby water bodies. More than $15 \%$ of the dyes are lost in wastewater during dyeing operations. This affects the surface esthetic merit of water and reduces light penetration, disturbing aquatic life and hindering photosynthesis [2]. Furthermore, some dyes are either toxic, mutagenic or/and carcinogenic [1].

It is known that $\mathrm{ZnO}$ is considered one of the most important oxide semiconductors with a band gap energy of 3-3.37 eV and a large exciton binding energy of $60 \mathrm{meV}$, having a high capacity to decompose organic pollutants under ultraviolet (UV) irradiation or sunlight exposure [3]. Due to 
its unique properties, $\mathrm{ZnO}$ is widely used for a large variety of applications such as light-emitting diodes, nanolasers, piezo-electric devices, UV-shielding materials, antibacterial agents, field effect transistors, solar cells and gas sensors [4-9]. Moreover, this semiconductor material is considered an excellent photocatalyst for the degradation of some organic dyes in wastewater. Many researchers have been trying to improve the photocatalytic properties of $\mathrm{ZnO}$ by doping with various metals (La, Sm, Er, Ce, N, Ag, and so on,) [10-13], combining with other metal oxides ( $\mathrm{NiO}, \mathrm{CeO}_{2}, \mathrm{SnO}_{2}$, $\mathrm{CuO}, \mathrm{CdO}, \mathrm{BaTiO}_{3}, \mathrm{NaNbO}_{3}, \mathrm{TiO}_{2}, \mathrm{Bi}_{2} \mathrm{O}_{3}, \mathrm{CuFe}_{2} \mathrm{O}_{4}$ ) [14] or with various carbon-based nanostructures (multi-walled carbon nanotubes (MWCNTs), graphene, graphene oxide) [15-18].

Recently, composite materials based on a combination of metal oxide semiconductor nanomaterials and different types of carbon species have been intensively used as photocatalysts due to their remarkable physico-chemical properties and potential applications in water purification and environmental protection [1,19-21]. In addition, it was demonstrated that the development of materials based on $\mathrm{ZnO}$ and carbon leads to an increase in the stability and efficiency of photocatalytic performance [1,19-21]. One of the simplest and cheapest methods of obtaining carbon-based materials is the use of polymer matrices followed by their carbonization at high temperature in $\mathrm{N}_{2}$ atmosphere. The most widely used polymer in obtaining $\mathrm{ZnO} /$ carbon-based nanomaterials is polyacrylonitrile (PAN) and is generally used as electrodes for supercapacitors [22-24]. It was shown that carbon nanofibers play an important role in energy conversion and storage, catalysis, sensors, adsorption/separation, and biomedical applications due to its good conductivity and chemical stability, tunable structural flexibility, and low cost [24,25].

The main goal of this study is to point out the remarkable results of carbon/ZnO-based catalysts in photocatalytic degradation, starting from easily accessible and low-cost materials. For this purpose, electrospun fiber mats of cellulose acetate butyrate $(\mathrm{CAB})$ were chosen for growing on them the desired $\mathrm{ZnO}$ nanostructures followed by their calcination at $600^{\circ} \mathrm{C}$ in $\mathrm{N}_{2}$ atmosphere for $30 \mathrm{~min}$. It is known that $\mathrm{CAB}$ is a thermoplastic polymer that softens in the first phases and then follows the degradation process. Moreover, it is a relatively inexpensive and accessible polymer. In this work, we aimed to produce a new type of material based on carbon/ZnO nanostructures that possess both adsorption and photocatalytic properties. To our knowledge, the development of carbon/ZnO nanostructures starting from $\mathrm{CAB}$ fiber mats obtained by electrospinning method, followed by $\mathrm{ZnO}$ nanostructures growth on them by dipping or hydrothermal method, and finally thermal calcination at $600{ }^{\circ} \mathrm{C}$ in $\mathrm{N}_{2}$ atmosphere for $30 \mathrm{~min}$, and then their testing for adsorption/degradation of organic dyes, have not been reported in the literature so far. The details on the structural, morphological, and optical properties of the carbon/ZnO nanostructures were achieved and discussed. Furthermore, the development of new hybrid materials based on carbon/ZnO nanostructures will add valuable insights to scientific research by combining adsorption and photocatalytic processes.

\section{Materials and Methods}

\subsection{Materials}

Cellulose acetate butyrate was obtained by commercial sources, Eastman product-CAB 551-0.2 - with $52 \mathrm{wt} \%$ butyryl content and $2 \mathrm{wt} \%$ acetyl content $(\mathrm{Mn}=30,000)$, zinc acetate $\left[\mathrm{Zn}\left(\mathrm{CH}_{3} \mathrm{COO}\right)_{2} \cdot 2 \mathrm{H}_{2} \mathrm{O}\right]$, purchased from Sigma-Aldrich (Taufkirchen, Germany), and ammonia $\left(\mathrm{NH}_{3}\right)$, purchased from Chemical Company SA, Iasi, Romania. All the chemicals were of reagent grade and were used without further purification.

\subsection{Carbon/ZnO Hybrid Nanostructures Preparation}

$\mathrm{CAB}$ fibers were prepared using the electrospinning method described in detail in previous work [26]. Briefly, the prepared viscous solution of 32\% CAB in 2-methoxyethanol as the solvent was transferred in a syringe of the electrospinning setup. The main parameters of the electrospinning process were: high voltage source $(25 \mathrm{kV})$, a $15 \mathrm{~cm}$ distance between the needle tip and the collector, 
and the flow-rate of $0.75 \mathrm{~mL} / \mathrm{h}$. Two methods were used in the growth of $\mathrm{ZnO}$ nanocrystals in $\mathrm{CAB}$ membranes: dipping and hydrothermal, followed by heat treatment at $600{ }^{\circ} \mathrm{C}$ for $30 \mathrm{~min}$ in $\mathrm{N}_{2}$ atmosphere to obtain carbon/ZnO hybrid nanostructures. The $\mathbf{M 1}$ sample was obtained using the dipping procedure which consists in successive dippings of the membrane in an ammonium zincate bath with $0.1 \mathrm{M}$ concentration and $\mathrm{pH}=11$, at room temperature, and then in a hot water bath, at about $97^{\circ} \mathrm{C}$, in 50 repeating cycles. After that, the sample $\mathbf{M 1}$ was thermally treated at $240{ }^{\circ} \mathrm{C}$ in the air for $1 \mathrm{~h}$.

The M2 sample was prepared by the hydrothermal method consisting of: (i) ZnO seeded onto CAB nanofiber mat by 10 dippings; (ii) growth of $\mathrm{ZnO}$ nanocrystals by a hydrothermal method in ammonium zincate bath at $\left(96-98^{\circ} \mathrm{C}\right)$ for $3 \mathrm{~h}$, followed by heat treatment at $240{ }^{\circ} \mathrm{C}$ in the air for $1 \mathrm{~h}$. The carbon/ZnO hybrid nanostructures M1 (T) and M2 (T) were developed after calcining of membrane $\mathbf{M} 1$ and $\mathbf{M} 2$ at $600{ }^{\circ} \mathrm{C}$ in $\mathrm{N}_{2}$ atmosphere for $30 \mathrm{~min}$. A representative diagram in preparing the carbon/ZnO hybrid materials is given in Scheme 1.

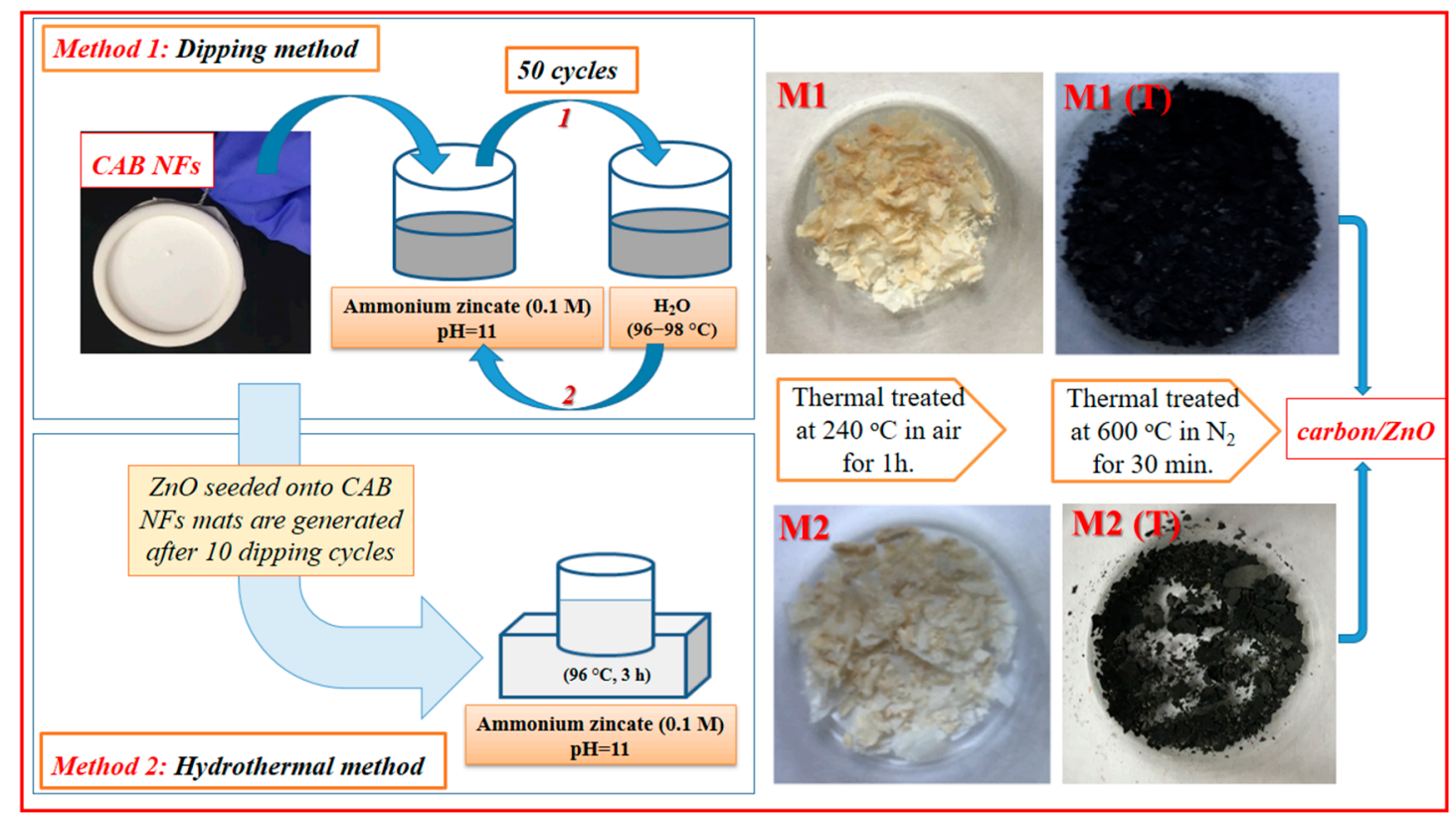

Scheme 1. Preparation of the Carbon/ZnO hybrid nanostructures.

\subsection{Characterization of Materials}

X-ray diffraction (XRD) analysis of carbon/ZnO hybrid nanostructures as made on a Shimadzu Lab X XRD-6000 diffractometer (Columbia, United States) with $\mathrm{CuK}_{\alpha}$ radiation $(\lambda=0.15418 \mathrm{~nm})$. The morphological properties of the obtained materials were demonstrated by scanning electron microscopy (SEM), using JEOL JSM 6362LV electron microscope (Japan). A Bruker Fourier transform infrared (FTIR) spectrometer (VERTEX 70, Ettlingen, Germany) equipped with a Deuterated Lanthanum $\alpha$ Alanine doped TriGlycine Sulphate (DLaTGS) detector was used for the analysis of the FTIR spectra of materials. Diffuse reflectance of carbon/ZnO hybrid materials was performed by ultraviolet-visible (UV-Vis) reflectance spectra measured on an Analytik Jena UV-Vis 210 spectrometer (Jena, Germany). Then, the band gap values were obtained using Kubelka-Munk function (KM) and by plotting $\left[F\left(R_{\infty}\right) h v\right]^{2}$ vs. $h v$.

\subsection{Photocatalytic Tests}

The adsorption and photocatalytic efficiency of carbon/ZnO hybrid nanostructures have been evaluated by degradation of Methylene Blue (MB), Congo Red (CR), and Rhodamine B (RhB) dye in aqueous solutions under visible light irradiation (100 W tungsten lamp source). More details on the 
degradation procedure and working conditions have been reported previously [27]. Initially, $5 \mathrm{mg}$ of each material were dispersed in $10 \mathrm{~mL}$ of dye solution with an initial concentration of $10 \mathrm{mg} / \mathrm{L} \mathrm{MB}$, $\mathrm{CR}$, and $5 \mathrm{mg} / \mathrm{L}$ of $\mathrm{RhB}$, respectively. Then, the solutions were stirred in the dark for $2 \mathrm{~h}$ to establish an adsorption-desorption equilibrium. The photocatalytic activity of the carbon/ZnO hybrid nanostructures was investigated by photodegradation of $M B, C R$, and RhB dyes using the same experimental setup and degradation procedure as reported by the authors in a previous work [28]. The UV-Vis absorption profiles for the initial dye solution and after exposure to visible light at various time intervals were obtained using UV-Vis spectrophotometer (SPECORD 210Plus, Analytik Jena, (Jena, Germany). Adsorption capacity $\left(\mathrm{Q}_{\mathrm{e}}, \mathrm{mg} / \mathrm{g}\right)$ and removal efficiency $(\%)$ for adsorption and degradation of $\mathrm{MB}$ were calculated using the following equations [29]:

$$
\begin{gathered}
q_{e}=\frac{\left(C_{0}-C_{e}\right) \times V}{m} \times 100, \\
\text { Color removal efficiency }(\%)=\frac{C_{0-} C_{e}}{C_{0}} \times 100,
\end{gathered}
$$

where $C_{0}$ is the initial $\mathrm{MB}$ concentration $(\mathrm{mg} / \mathrm{L})$ and $C_{e}$ is the $\mathrm{MB}$ concentration at the time $t(\mathrm{mg} / \mathrm{L})$, $m$ is the catalyst mass $(\mathrm{g})$, and $V$ is the solution volume (L).

\section{Results}

\subsection{X-ray Diffraction (XRD) Characterization}

X-ray diffraction (XRD) patterns of M1 (T) and M2 (T) materials are shown in Figure 1 and confirm the crystalline phase of $\mathrm{ZnO}$ with the hexagonal wurtzite structure.

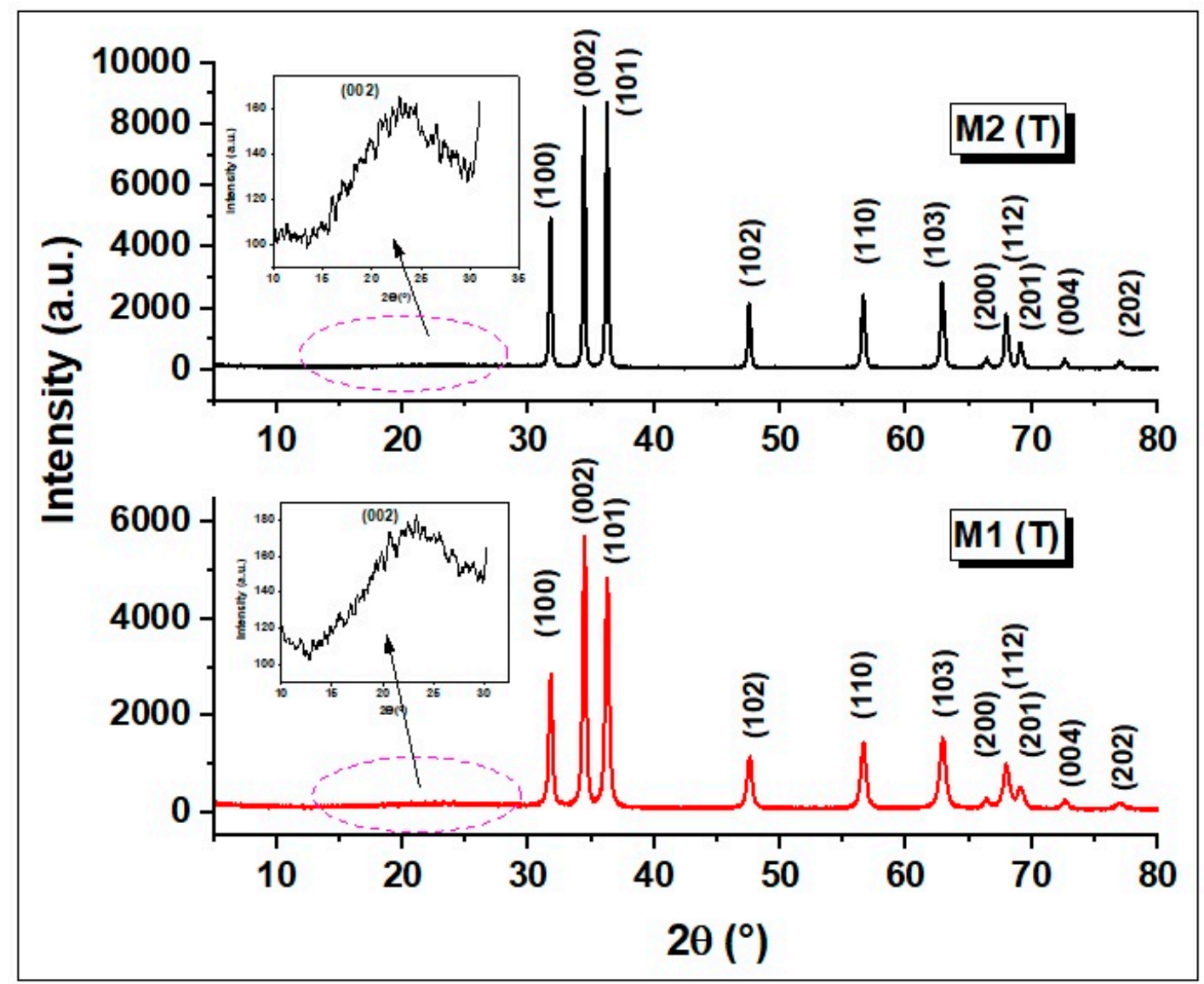

Figure 1. X-ray diffraction (XRD) patterns of M1 (T) and M2 (T) samples. 
The peaks corresponding to this structure are found at $2 \theta$ of $31.78^{\circ}(100), 34.46^{\circ}(002), 36.26^{\circ}$ $(101), 47.64^{\circ}(102), 56.62^{\circ}(110), 62.90^{\circ}(103)$, and $67.10^{\circ}(112)$ and belong to pure $\mathrm{ZnO}$ structure Joint Committee on Powder Diffraction Standards (JCPDS No. 89-1397). The main parameters that can be deduced from the analysis of X-ray diffractograms are summarized in Table 1, and for their calculation, the diffraction peaks corresponding to the Miller indices (100), (002) and (101) were used. In addition, to estimate the crystallite size (D), the spacing distance between crystallographic planes $\left(\mathrm{d}_{\mathrm{hkl}}\right)$, the lattice parameters $a$ and $c$, the $\mathrm{Zn}-\mathrm{O}$ bond length $(\mathrm{L})$ and the microstrain $(\varepsilon)$, the authors utilized the equations described in detail in previous work [11].

Table 1. Structural parameters of carbon/ZnO nanostructured materials.

\begin{tabular}{|c|c|c|c|c|c|c|c|c|}
\hline \multirow{2}{*}{ Sample } & \multirow{2}{*}{$2 \theta\left({ }^{\circ}\right)$} & \multirow{2}{*}{$\mathrm{d}_{\mathrm{hkl}}(\AA)$} & \multirow{2}{*}{$D(n m)$} & \multicolumn{3}{|c|}{ Lattice Parameters } & \multirow{2}{*}{$\varepsilon(\%)$} & \multirow{2}{*}{$L(n m)$} \\
\hline & & & & a (̊̊) & c ( $(\AA)$ & $c / a$ & & \\
\hline \multirow{3}{*}{ M1 (T) } & 31.78 & 2.813 & 22.88 & \multirow{3}{*}{3.249} & \multirow{3}{*}{5.201} & \multirow{3}{*}{1.601} & \multirow{3}{*}{0.564} & \multirow{3}{*}{1.954} \\
\hline & 34.46 & 2.6 & 20.73 & & & & & \\
\hline & 36.26 & 2.475 & 21.39 & & & & & \\
\hline \multirow{3}{*}{ M2 (T) } & 31.76 & 2.815 & 36.13 & \multirow{3}{*}{3.251} & \multirow{3}{*}{5.207} & \multirow{3}{*}{1.602} & \multirow{3}{*}{0.353} & \multirow{3}{*}{1.957} \\
\hline & 34.42 & 2.603 & 33.17 & & & & & \\
\hline & 36.24 & 2.476 & 30.94 & & & & & \\
\hline
\end{tabular}

From the analysis of the lattice parameters $a$ and $c$ presented in Table 1 , it can be seen that they do not show significant changes after the carbonization of the organic material, which confirms that the hexagonal wurtzite structure of $\mathrm{ZnO}$ is maintained. Besides, the ratio $c / a$ is practically constant, which indicates that the hexagonal wurtzite structure of $\mathrm{ZnO}$ structure does not change. Significant changes can be observed for the crystallite size (D) and the microstrain $(\varepsilon)$ parameter. The crystallite size values vary between $22.88 \mathrm{~nm}$ (corresponding to M1 (T) sample) and $36.13 \mathrm{~nm}$ (registered for M2 (T)), respectively. In addition, a discreet broadening of M1 (T) signals was observed which may be ascribed to the presence of a star-like shape of the ZnO crystallites, having a more multidirectional distribution. Moreover, it is well known that a smaller size of crystallites will induce a broadening of the signal. The microstrain $(\varepsilon)$ parameter increases from 0.353 corresponding to sample M2 (T) to 0.564 for sample M1 (T), probably due to the shape change of the nanostructures and the carbon content of the samples. XRD analysis (Figure 1 (inset)) suggests the presence of carbon in both samples with broad diffraction peaks between $20^{\circ}$ and $30^{\circ}$, which was assigned to the (002) lattice planes in the graphitic structure [20]. A significant difference can be observed in the value obtained for crystallites size in XRD compared to those observed in SEM. It is known that the formation of these nanostructures (star-like and nanorod shapes in our case) takes place in two stages: nucleation and growth. In the first stage, small nuclei are formed which, as the reaction progresses, these nuclei grow further to produce star-like and nanorod $\mathrm{ZnO}$ crystallites, which are the building blocks for the crystals observed in SEM images [30-34].

\subsection{Fourier Transform Infrared (FTIR) Analysis}

Figure 2 shows the FTIR spectra of CAB nanofibres and carbon/ZnO corresponding to M1 (T) and M2 (T) nanostructured materials registered between 370 and $4000 \mathrm{~cm}^{-1}$.

It is known that $\mathrm{ZnO}$ has an intense broad band between $420 \mathrm{~cm}^{-1}$ and $510 \mathrm{~cm}^{-1}$ due to two transverse optical stretching modes of $\mathrm{ZnO}[35,36]$. In our case, two characteristic absorption bands located at $397 \mathrm{~cm}^{-1}$ and $497 \mathrm{~cm}^{-1}$ were observed corresponding to $\mathbf{M} 2$ (T) material, as well as an absorption band at $424 \mathrm{~cm}^{-1}$ of $\mathbf{M 1}(\mathrm{T})$, respectively. The occurrence of these two bands in the FTIR spectrum for sample M2 (T) it is due to the nanorod shape nanostructures. Wu et al., [37] state that the transition from 0D nanostructures (nanoparticles) to 1D (nanorod) leads to the appearance of two main absorption maxima in FTIR spectra in this range. The presence of vibration bands at the wavenumbers 
of $1614 \mathrm{~cm}^{-1}$ and $1529 \mathrm{~cm}^{-1}$ assigned to the asymmetric stretching vibration and symmetric stretching vibration of $\mathrm{C}=\mathrm{C}$ bonds indicates the removal of functional groups and the successful carbonization of the new material, as it was confirmed by other authors for similar systems [38]. This aspect is very important since amorphous carbon is known as a very good adsorbent [39]. The absorption band located at $3425 \mathrm{~cm}^{-1}$ belongs to the stretching vibration of $\mathrm{O}-\mathrm{H}$ groups due to the absorbed water on the surface of the carbon/ZnO materials. The bands around $1083 \mathrm{~cm}^{-1}$ are associated with bending vibrations of various ether bridges coming from the residual polymeric material.
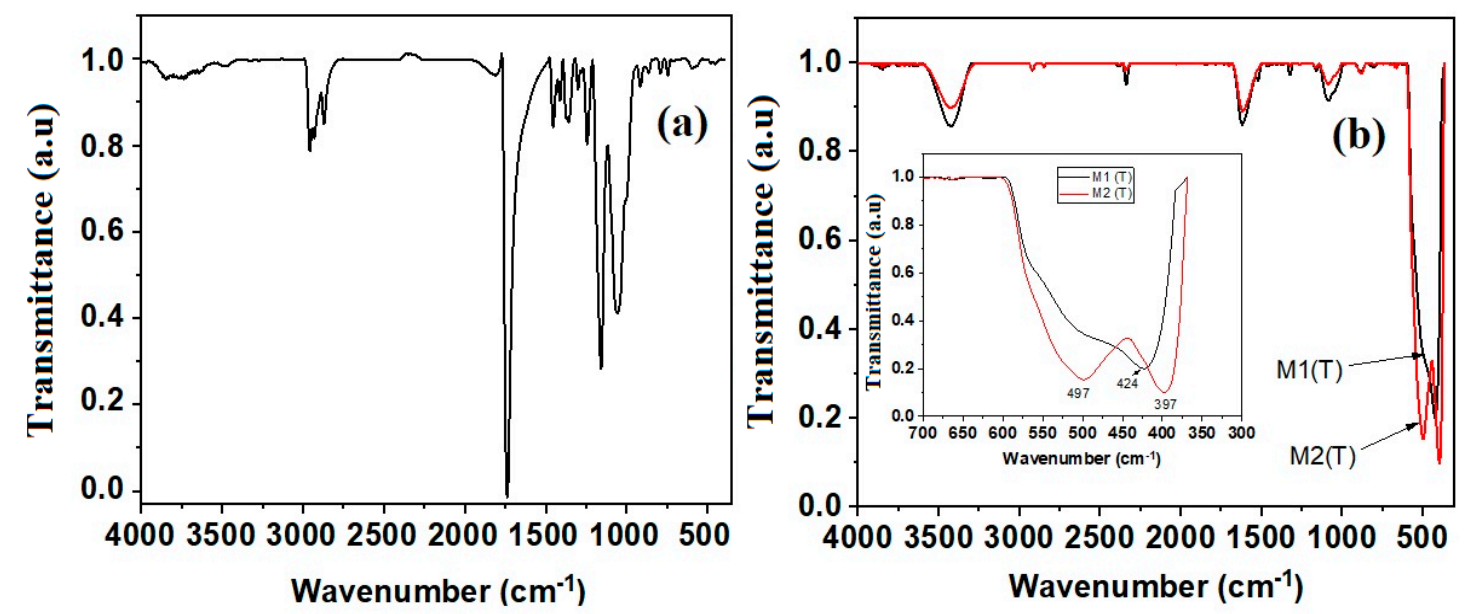

Figure 2. Fourier transform infrared (FTIR) spectra of CAB nanofibres (a) and carbon/ZnO; (b) for the two types of nanostructures M1 (T) and M2 (T), respectively.

\subsection{Morphological Characterization}

The SEM image of the CAB microfiber obtained immediately after the electrospinning process is shown in Figure 3.

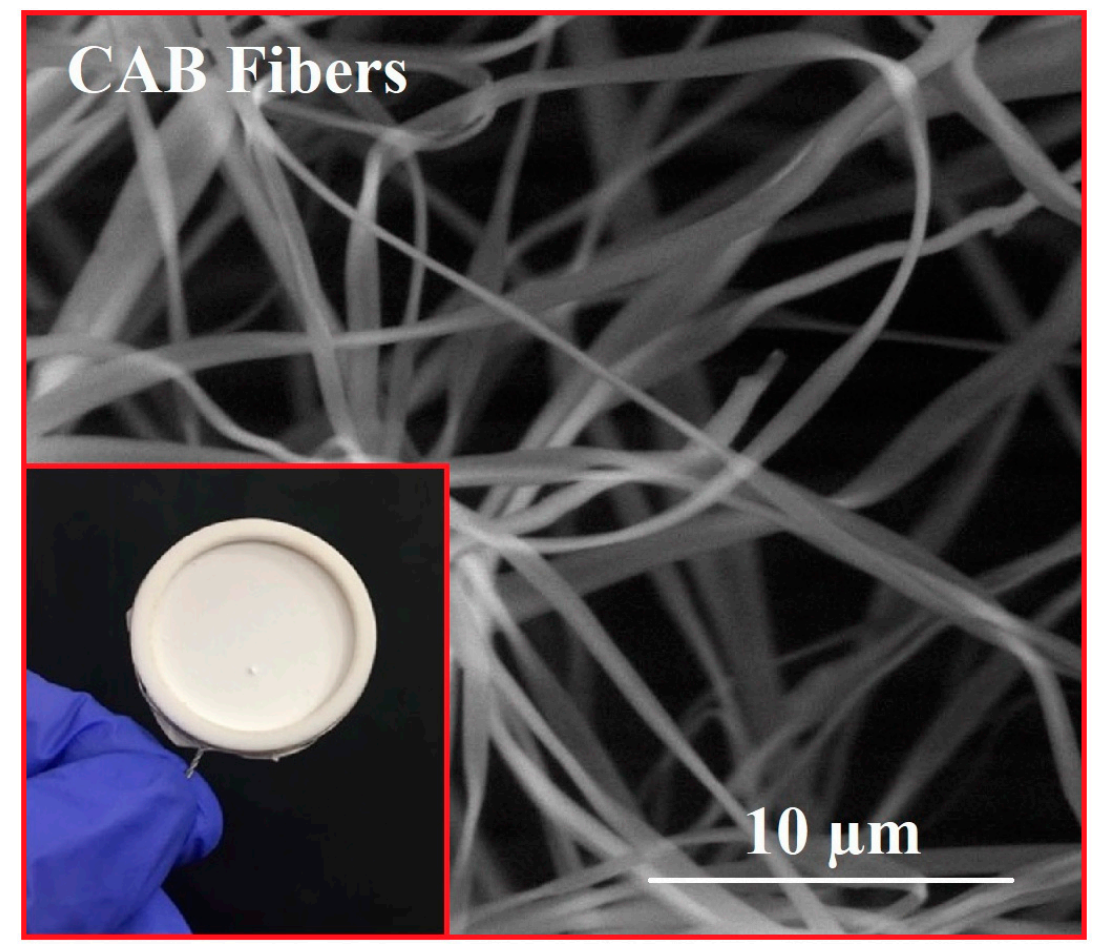

Figure 3. Scanning electron microscope (SEM) image of cellulose acetate butyrate (CAB) microfiber mats obtained by the electrospinning method from a mixture of $32 \%$ polymer and 2-methoxyethanol. 
This micrograph confirms the formation of a membrane with uniform and smooth microfibers having dimensions of $1 \mu \mathrm{m}$. After this, star-shaped crystals and nanorods were grown on these membranes by dipping and hydrothermal methods, followed by calcination at $240{ }^{\circ} \mathrm{C}$ in the air for $1 \mathrm{~h}$. SEM images shown in Figure 4 for hybrid $\mathrm{CAB} / \mathrm{ZnO}$ nanostructures obtained by the dipping method indicate a structure composed of $\mathrm{ZnO}$ nanocrystals with a star-like shape. It can be observed that the same structure was maintained after calcination at $600{ }^{\circ} \mathrm{C}$ in $\mathrm{N}_{2}$ atmosphere for $30 \mathrm{~min}$ for M1 (T) nanostructure (Figure 4).
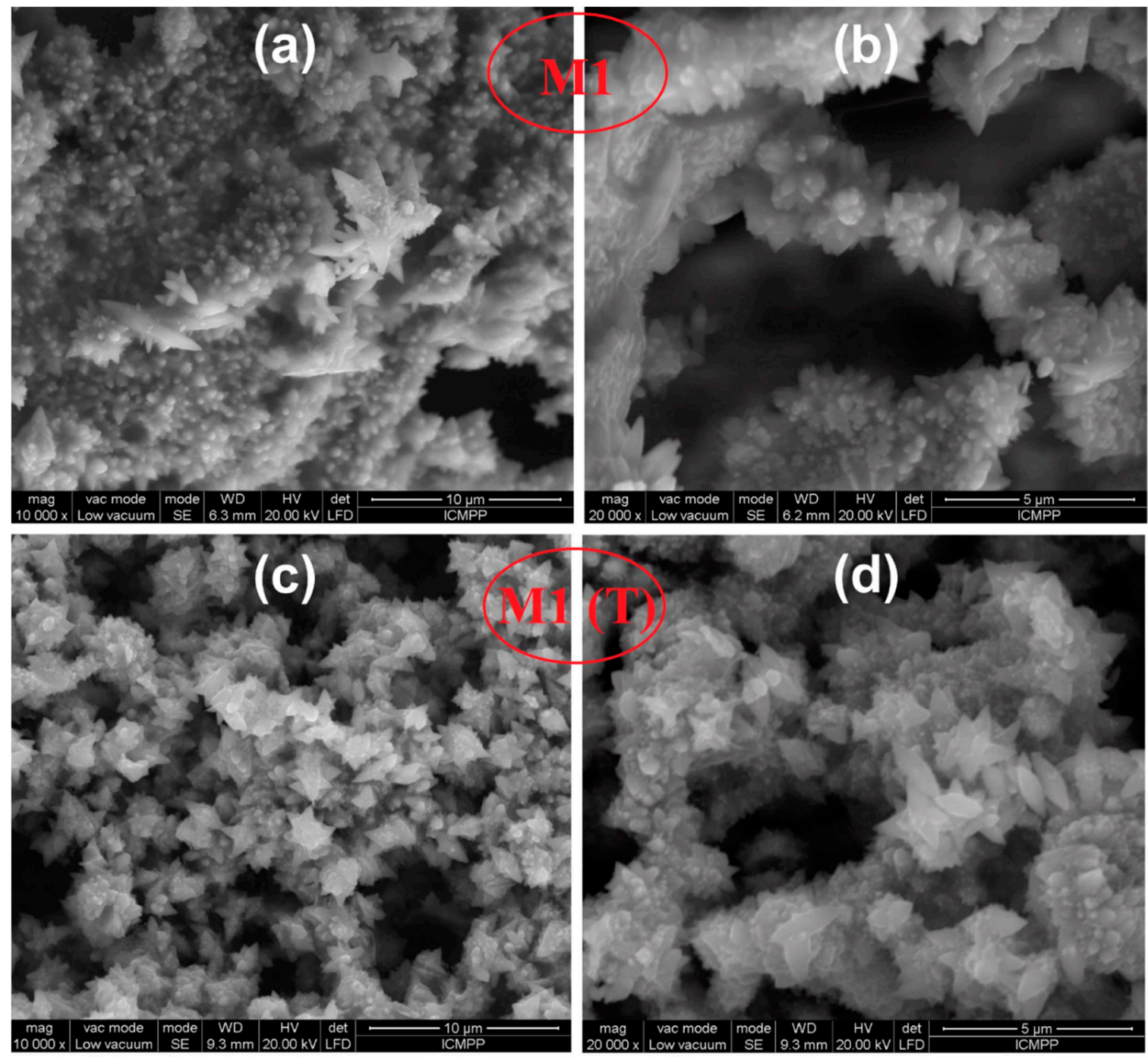

Figure 4. SEM images of $\mathrm{CAB} / \mathrm{ZnO}$ hybrid nanostructures obtained by the dipping method after thermal treating at $240{ }^{\circ} \mathrm{C}$ in the air for $1 \mathrm{~h}((\mathbf{a})$ and (b) for M1), and carbon/ZnO after thermally treating at $600{ }^{\circ} \mathrm{C}$ in $\mathrm{N}_{2}$ for $30 \mathrm{~min}((\mathbf{c})$ and (d) for $\mathrm{M1}$ (T)).

The materials obtained by the hydrothermal method (M2 and M2 (T)) show a nanorod type structure with an average diameter of about $700 \mathrm{~nm}$ and lengths around $5 \mu \mathrm{m}$ according to the SEM images represented in Figure 5. 

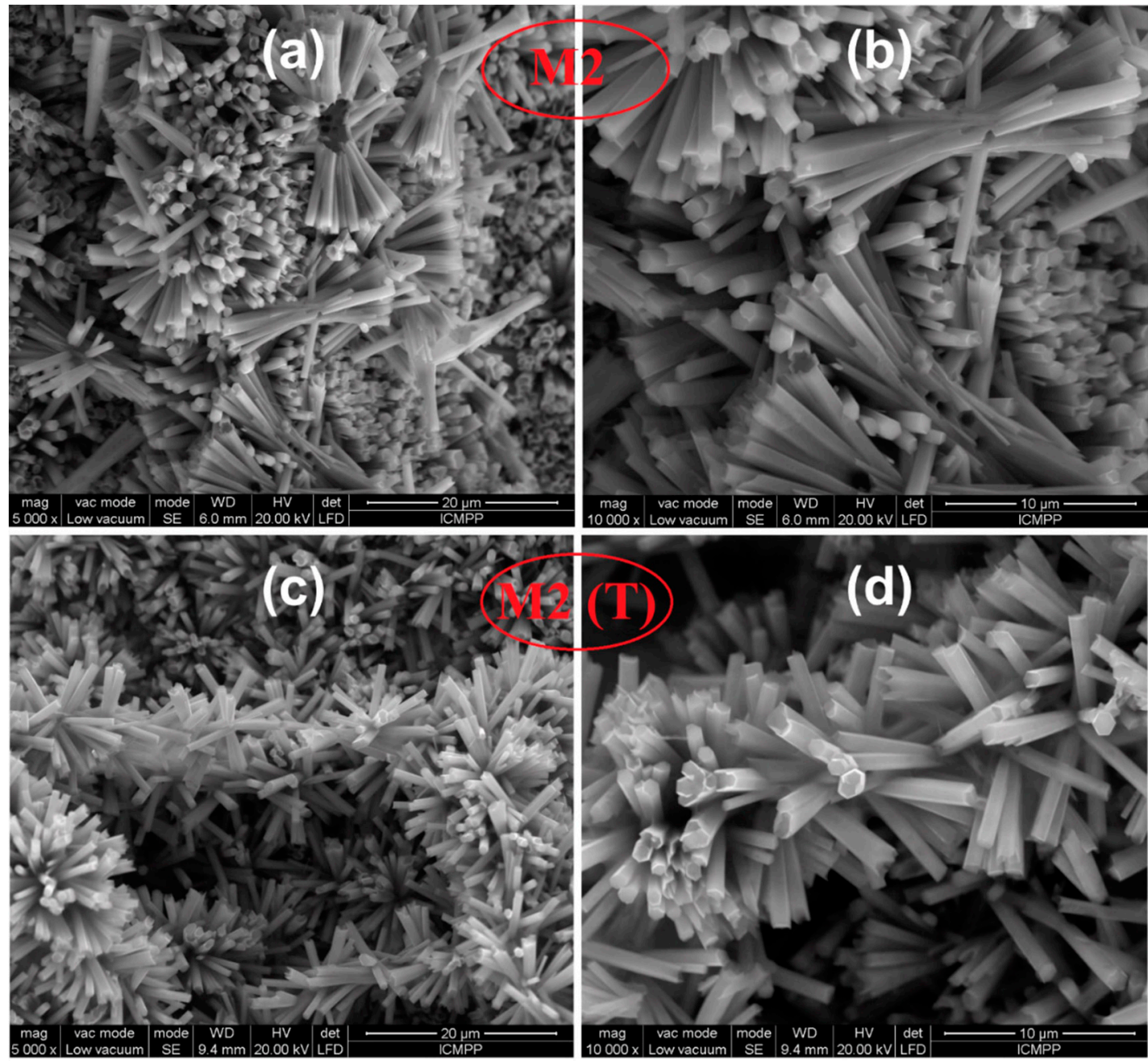

Figure 5. SEM analysis of $\mathrm{CAB} / \mathrm{ZnO}$ hybrid nanostructures obtained by the hydrothermal method after thermal treating at $240{ }^{\circ} \mathrm{C}$ in the air for $1 \mathrm{~h}((\mathbf{a})$ and (b) for M2), and carbon/ZnO after thermally treating at $600{ }^{\circ} \mathrm{C}$ in $\mathrm{N}_{2}$ for $30 \mathrm{~min}((\mathbf{c})$ and (d) for $\mathbf{M} 2(\mathrm{~T}))$.

\subsection{Optical Properties}

The most important parameter that significantly influences the photodegradation process is represented by the energy band gap of materials. The value of this parameter was assessed by UV-Vis reflectance experiments, followed by applying the Kubelka-Munk equation (Equation (3)) and Tauc relation (Equation (4)) [40].

$$
F\left(R_{\infty}\right)=\frac{\left(1-R_{\infty}\right)^{2}}{2 R_{\infty}}
$$

where $F\left(R_{\infty}\right)$ is the so-called remission or Kubelka-Munk function and $R_{\infty}$ is the reflectance of the samples.

$$
\left[F\left(R_{\infty}\right) h v\right]^{2}=A\left(h v-E_{\mathrm{g}}\right),
$$

where $A$ is a constant, $E_{\mathrm{g}}$ is the optical band gap of the material.

The energy band gap values of carbon/ZnO nanostructures were obtained by plotting $\left.\left[F\left(R_{\infty}\right) h v\right)\right]^{2}$ versus $h v$ and extrapolating the linear portion of the absorption edge to find the intercept with photon energy axis as shown in Figure 6. 

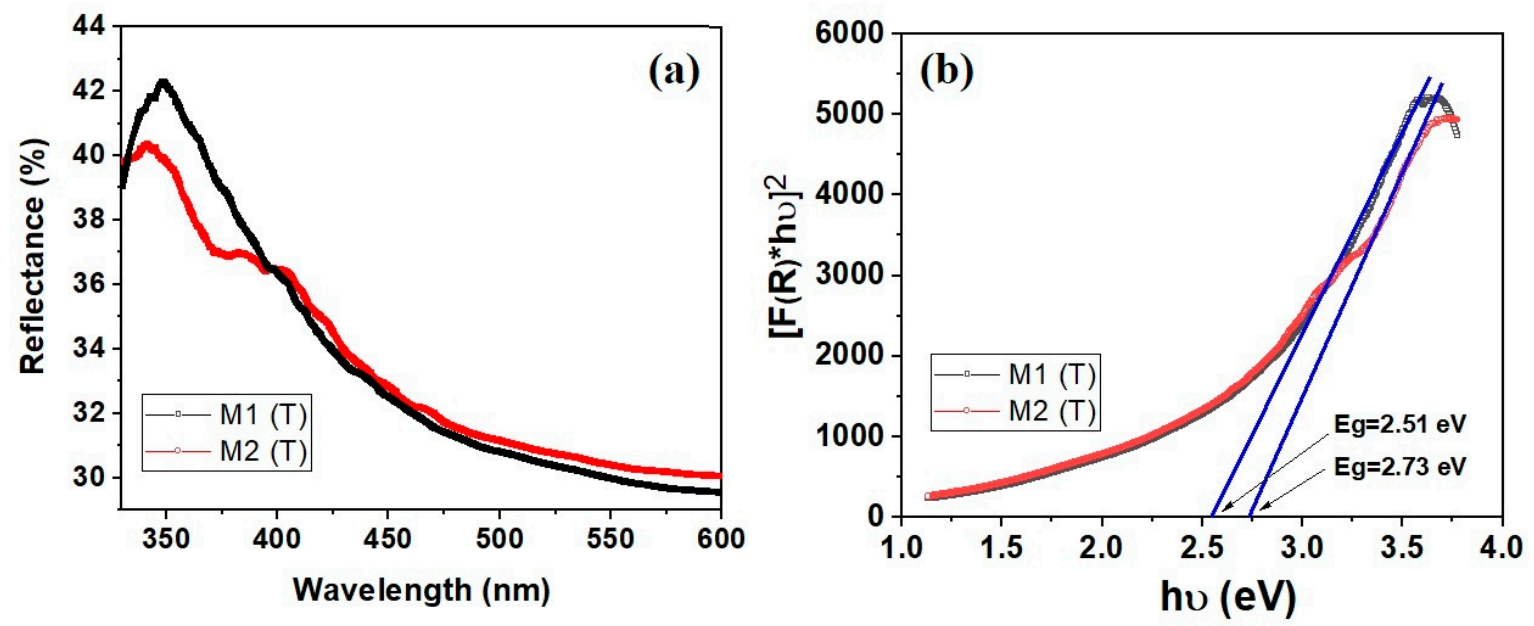

Figure 6. Optical properties of carbon/ZnO nanostructures (a) diffuse reflectance ultraviolet-visible (UV-Vis) spectra and (b) plot of $[F(R) h v]^{2}$ versus hv and band gap determination.

A significant decrease in $E_{\mathrm{g}}$ value was observed for carbon/ZnO hybrid materials. Thus, for M1 (T) the $E_{\mathrm{g}}$ was found to be $2.51 \mathrm{eV}$, while for $\mathbf{M} 2$ (T) $2.73 \mathrm{eV}$, respectively. These values are lower compared to those obtained for $\mathrm{CAB} / \mathrm{ZnO}(3.21 \mathrm{eV}$ and $3.31 \mathrm{eV})$ nanostructures reported in our previous works [26]. This decrease of $E_{\mathrm{g}}$ could be ascribed to the enhanced conductivity, confirmed by other authors for similar systems [41]. It can be seen that the presence of carbon in $\mathrm{ZnO}$ nanostructures leads to a change in the electronic energy levels. For example, similar results were obtained for hybrid RGO-ZnO where $E_{\mathrm{g}}$ decreases to $2.16 \mathrm{eV}$ as compared to pure $\mathrm{ZnO}(3.06 \mathrm{eV})$ [42]. Another study reported by Rahimi et al., [15] showed that the $E_{\mathrm{g}}$ value decreases from $3.2 \mathrm{eV}(\mathrm{ZnO})$ to $2.8 \mathrm{eV}$ for $\mathrm{ZnO}$ nanorod/graphene quantum dot composites, respectively. The authors associate this phenomenon to the formation of $\mathrm{Zn}-\mathrm{O}-\mathrm{C}$ or $\mathrm{Zn}-\mathrm{C}$ chemical bonds in the composites obtained.

\subsection{Photoluminescence Study}

The analysis of the photoluminescence properties is closely related to the photocatalytic properties of the developed catalysts and help us to understand the recombination processes of the photogenerated electron-hole pairs. Therefore, the emission spectra obtained under $300 \mathrm{~nm}$ and $320 \mathrm{~nm}$ excitation wavelengths are presented in Figure 7.
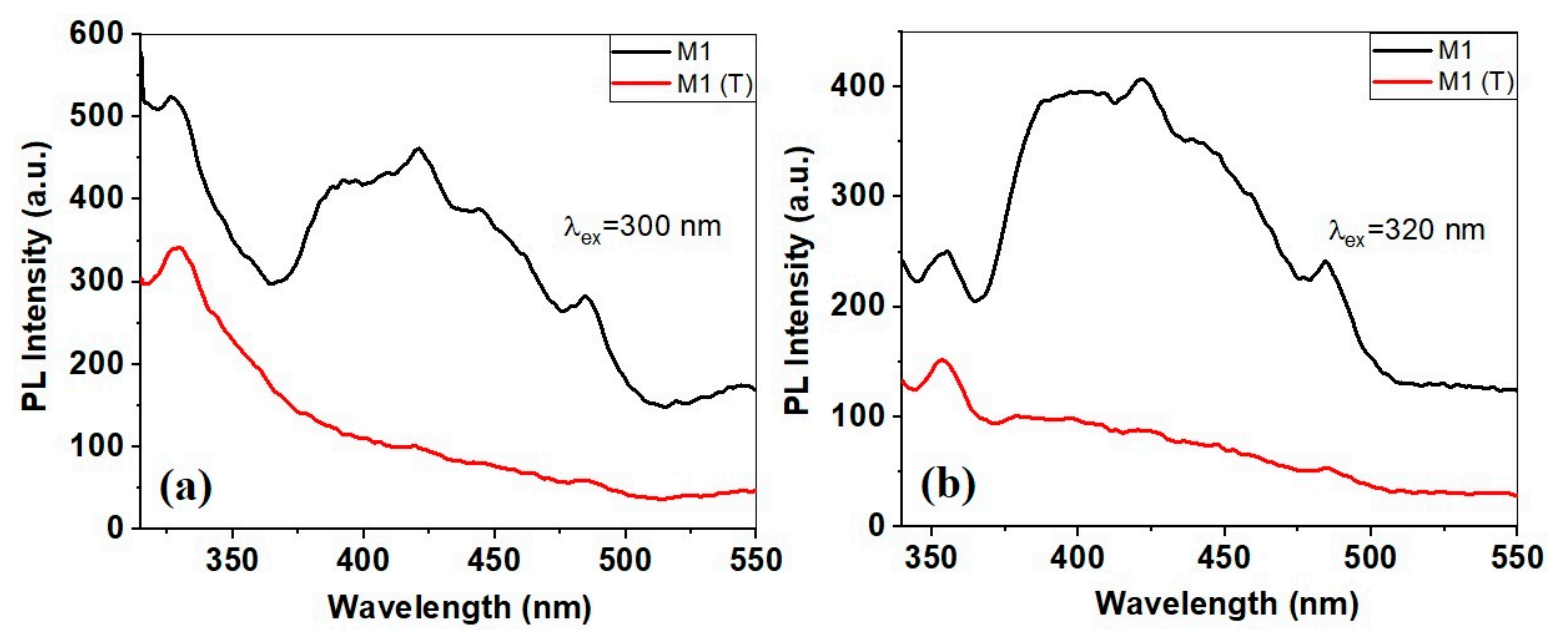

Figure 7. Photoluminescence spectra of $\mathrm{CAB} / \mathrm{ZnO}$ and Carbon/ZnO nanostructures as a function of excitation wavelength 300 (a), and $320 \mathrm{~nm}(\mathbf{b})$. 
It can be seen that the emission spectra corresponding to sample $\mathbf{M 1}(\mathrm{CAB} / \mathrm{ZnO})$ show several emission bands at $327 \mathrm{~nm}, 391 \mathrm{~nm}, 421 \mathrm{~nm}, 444 \mathrm{~nm}$, and $484 \mathrm{~nm}$, respectively. The UV emission bands from $327 \mathrm{~nm}$ (Figure 7a) and $350 \mathrm{~nm}$ (Figure 7b) can be assigned the near band edge (NBE) emission, and may be due to free exciton recombination [43]. It is known that the emission bands in the visible spectrum are due to different intrinsic defects of $\mathrm{ZnO}$ nanostructures, which include oxygen vacancies $\left(V_{\mathrm{O}}\right)$, zinc vacancies $\left(V_{\mathrm{Zn}}\right)$, oxygen interstitials $\left(O_{\mathrm{i}}\right)$, zinc interstitials $\left(Z n_{\mathrm{i}}\right)$ and oxygen antisites $\left(\mathrm{O}_{\mathrm{Zn}}\right)$ [27].

The emission spectrum of carbon/ZnO sample provides weak photoluminescence compared to sample M1. This means that the absorbed light is used efficiently in generating hole-electron pairs, without losing in the form of photoluminescence. The band located in the blue region practically disappeared, and the bands at 327 (Figure 7a), $350 \mathrm{~nm}$ (Figure 7b) and $484 \mathrm{~nm}$ become very weak. According to other studies [15], this large decrease of photoluminescence of carbon/ZnO nanostructures may indicate a large decrease in the radiative recombination rate of electron-hole pairs.

\subsection{Adsorption/Photocatalytic Properties}

3.6.1. Adsorption/Photocatalytic Properties of Carbon/ZnO Hybrid Nanostructures for Degradation of Organic Pollutants

In the first stage of this study, the degradation efficiency of rhodamine $B\left(C_{0}=5 \mathrm{mg} / \mathrm{L}\right)$ for the starting samples (M1 and M2) and the calcined samples (M1 (T) and M2 (T)) in $\mathrm{N}_{2}$ was performed. The blank test (without catalyst) was initially evaluated after $4 \mathrm{~h}$ and showed that the intensity of the absorption band of RhB decreases slightly, yielding 1.39\% in dye degradation. Figure 8 shows the evolution of the absorption spectra of all materials after adsorption for two hours to establish the adsorption/desorption equilibrium of dye on the photocatalyst surface, followed by the degradation between 4 and $20 \mathrm{~h}$ depending on the efficiency of the samples.

From the analysis of the samples, it was noticed that for the samples M1 and M2 the adsorption process was very small (5.56\% for M1 and 1.08\% corresponding to M2). A significant increase in the adsorption process occurs after the carbonization of materials, yielding adsorption efficiency between 89.61\% (M1 (T)) and 46.59\% (M2 (T)), respectively. This increase was attributed to the inclusion of carbon in the newly developed hybrid materials. It is known that carbon-based materials lead to an increase in adsorption, conductivity, as well as a decrease in the energy band gap [25]. The most outstanding result, which cumulates both the adsorption/photocatalytic processes, was registered for M1 (T) with an efficiency of up to $98.34 \%$.

In the next part of this study, the effect of the initial MB dye concentration on the M1 (T) nanostructure activity was investigated. To assess each contribution, adsorption and photodegradation, measurements for five initial dye concentrations (7, 10, 13, 17, and $20 \mathrm{mg} / \mathrm{L})$ were performed. Figure 9 shows that the color removal efficiency in the adsorption process increased with the decrease in the initial dye concentration. Initially, it can suggest that this process is apparently significant, but after calculating, the adsorption constant $Q_{e}(\mathrm{mg} / \mathrm{g})$ for all concentrations was the same (12-13 mg/g) for all samples. Under these conditions, in the next part of this work, the photodegradation of MB dye was evaluated without taking into account the adsorption process. 

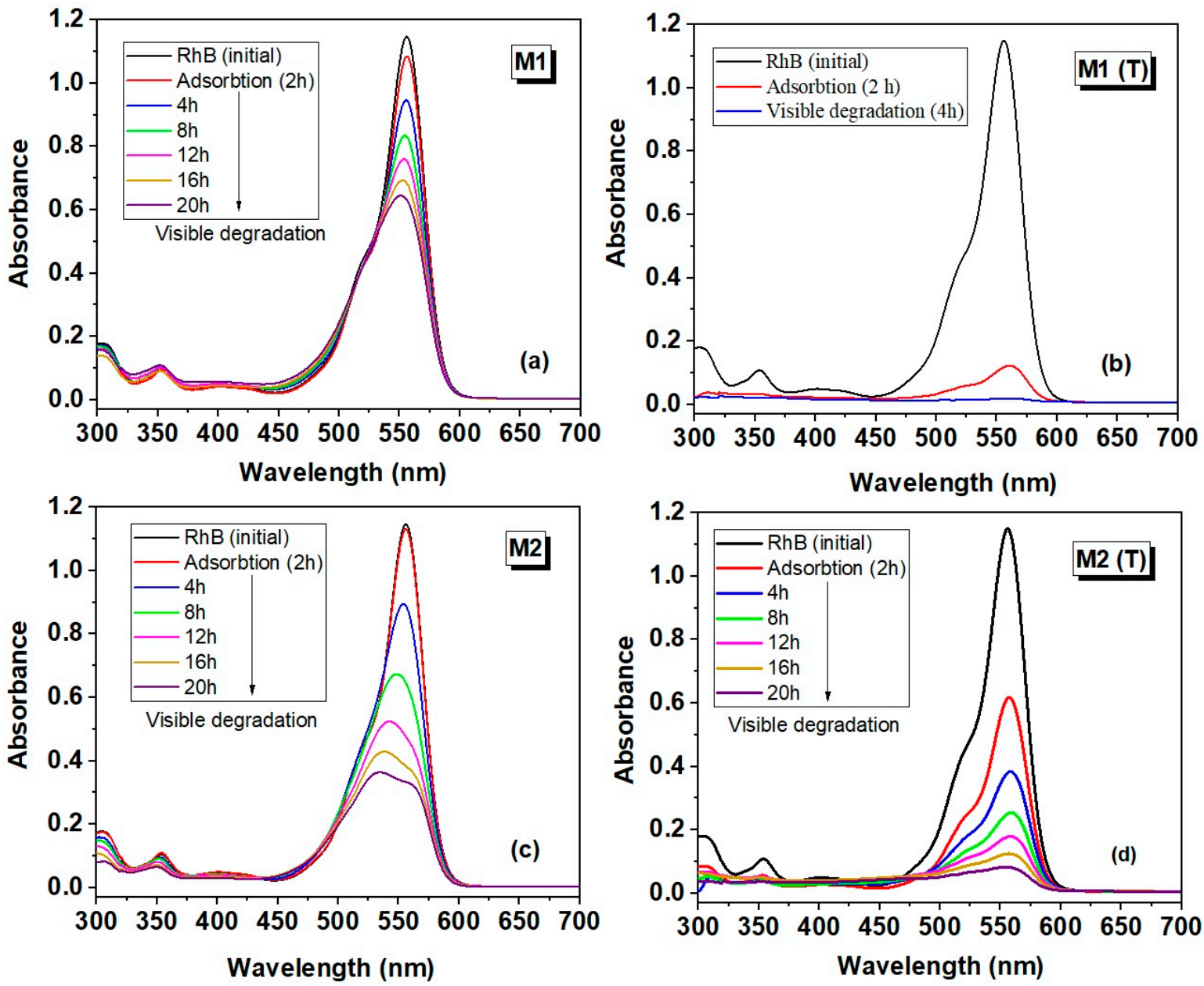

Figure 8. UV-Vis absorption spectra of Rhodamine B (RhB) recorded after adsorption (2h) (in dark) and photodegradation process under visible light irradiation (up to $20 \mathrm{~h}$ ) ) for the materials obtained by dipping method (M1, M1 (T)) and hydrothermal method (M2, M2 (T)): (a,c) before calcination and $(\mathbf{b}, \mathbf{d})$ after calcination.
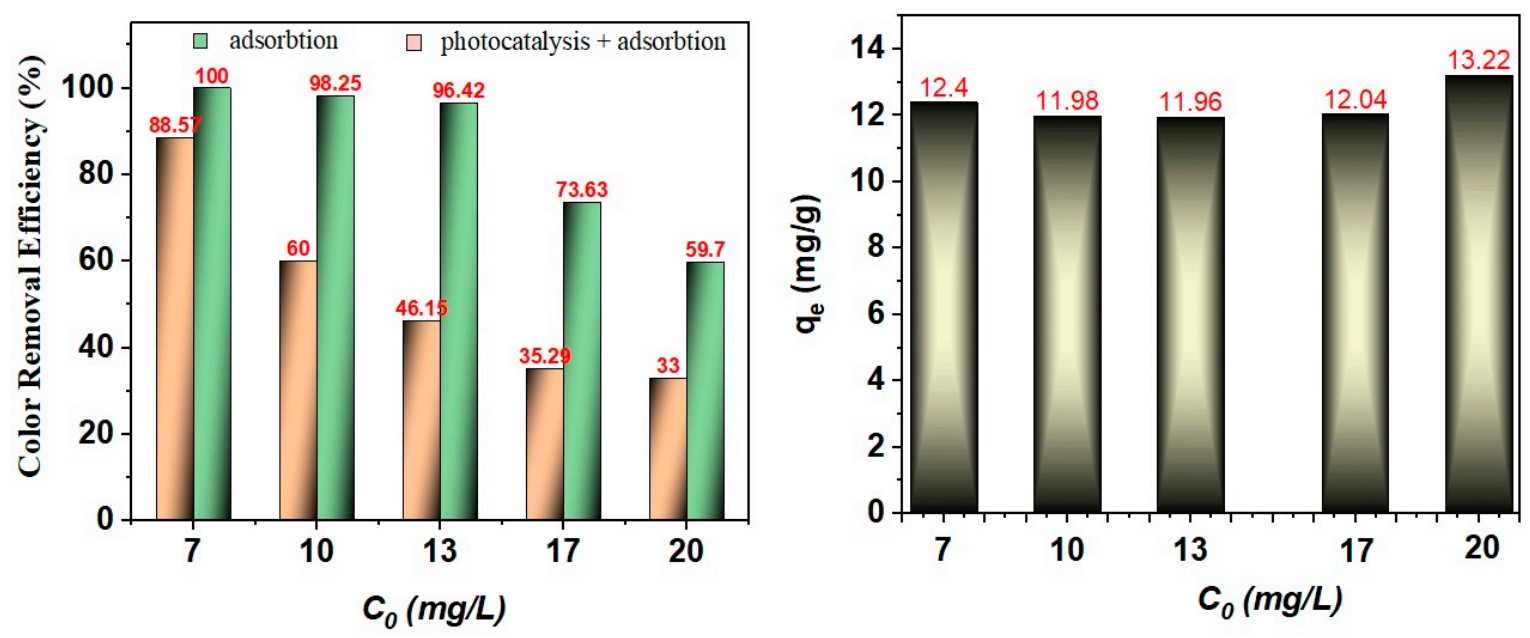

Figure 9. Color removal efficiency after adsorption and photodegradation (left), and the maximum adsorption capacity of M1 (T) catalyst (right) for Methylene Blue (MB) dye. 
3.6.2. Photocatalytic Activity of Carbon/ZnO Hybrid Nanostructures for Degradation of Methylene Blue (MB) Dye

Figure 10a,b show the evolution of the UV-Vis absorption spectra for MB dye degradation in presence of both catalysts (M1 (T) and M2 (T)) under visible light irradiation for $4 \mathrm{~h}$ (without previous the $2 \mathrm{~h}$ adsorption process).

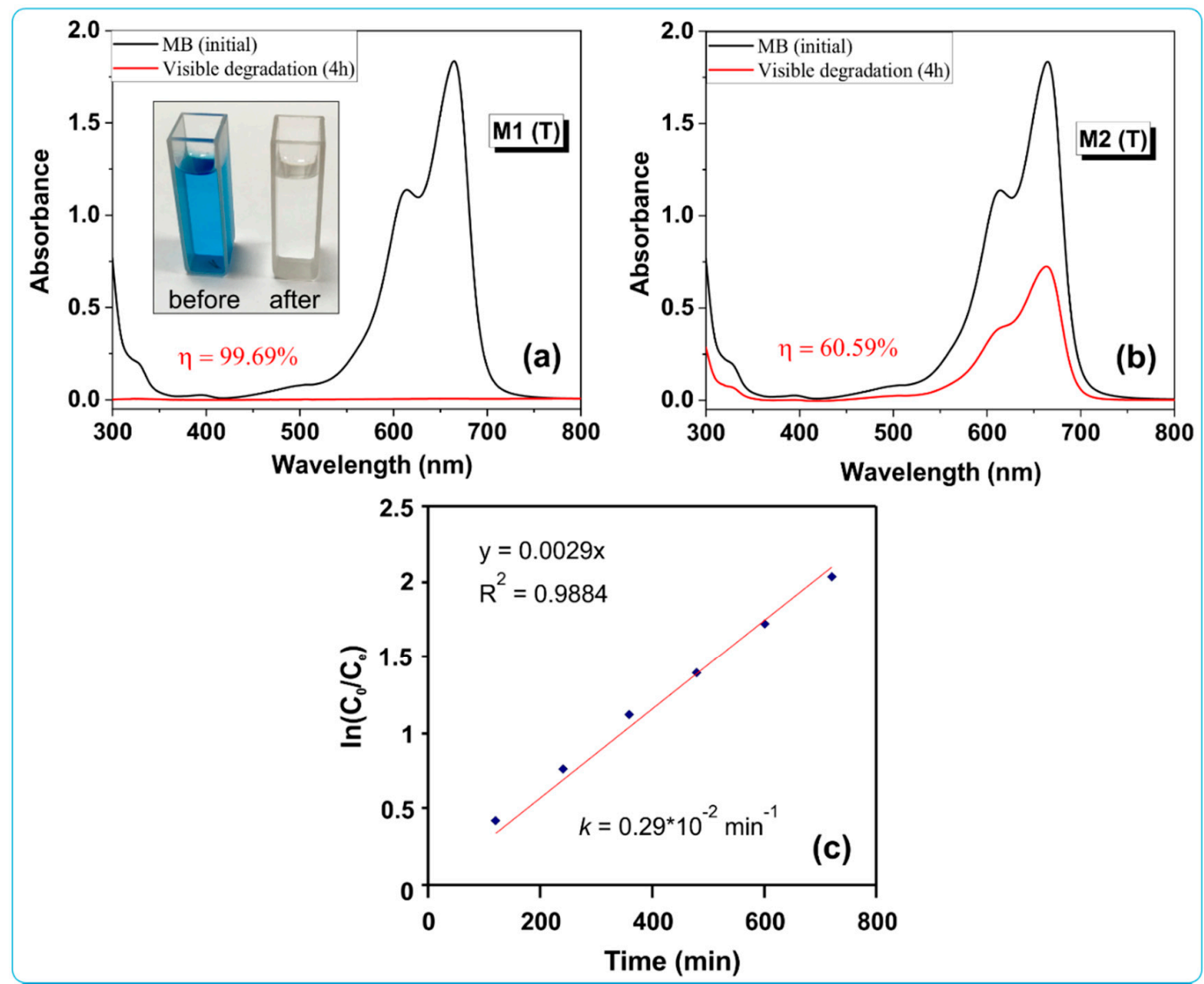

Figure 10. UV-Vis absorption spectra after visible light irradiation for $4 \mathrm{~h}$ in the presence of sample M1 (T) (a) and M2 (T) (b), and the degradation kinetics for M1 (T) sample (c).

It was observed that after $4 \mathrm{~h}$ of visible light irradiation the absorption band at $665 \mathrm{~nm}$ decreases to almost 0, reaching a maximum efficiency of $99.69 \%$ for sample M1 (T). The M2 (T) sample reveals a slower decrease in the degradation efficiency, yielding $60.59 \%$. We consider that this difference between the values of the photocatalytic degradation efficiency would be due to the different shapes and the presence of carbon in the nanostructures, giving a lower value of the band gap for the M1 (T) sample.

Quantitative estimation of degradation kinetics of $\mathrm{MB}$ dye was performed using a pseudo-first-order kinetics model according to the following equation: $\ln \left(C_{0} / C_{t}\right)=k t, C_{0}$ is concentration of dye solution before irradiation, $C_{t}$ is concentration of dye solution after $\mathrm{t}$ minutes of irradiation, and $\mathrm{k}$ is the pseudo-first-order rate constant. The value of the reaction constant for sample M1 (T) was calculated by plotting $\ln \left(C_{0} / C_{t}\right)$ versus irradiation time $t$ (see Figure $10 \mathrm{c}$ ) and was found to be $0.29 \times 10^{-2} \mathrm{~min}^{-1}$ with the value $R^{2}=0.9884$ attributed to a pseudo first-order reaction kinetics.

To demonstrate the adsorption/photocatalytic properties of the new carbon/ZnO hybrid nanostructures it was performed experiments in photocatalytic degradation of $\mathrm{MB}$ (initial concentration $10 \mathrm{mg} / \mathrm{L}), \operatorname{RhB}(5 \mathrm{mg} / \mathrm{L})$ and CR $(10 \mathrm{mg} / \mathrm{L})$ as a test reaction. Very good results were recorded for the degradation of all dyes tested with the following maximum color removal efficiency (both adsorption and adsorption + photocatalytic processes after $4 \mathrm{~h}$ of irradiation): $97.97 \%$ for $\mathrm{MB}\left(C_{0}=10 \mathrm{mg} / \mathrm{L}\right)$, $98.34 \%$ for $\mathrm{RhB}\left(C_{0}=5 \mathrm{mg} / \mathrm{L}\right)$, and $91.93 \%$ for $\mathrm{CR}\left(C_{0}=10 \mathrm{mg} / \mathrm{L}\right)$, respectively (Figure 11$)$. 

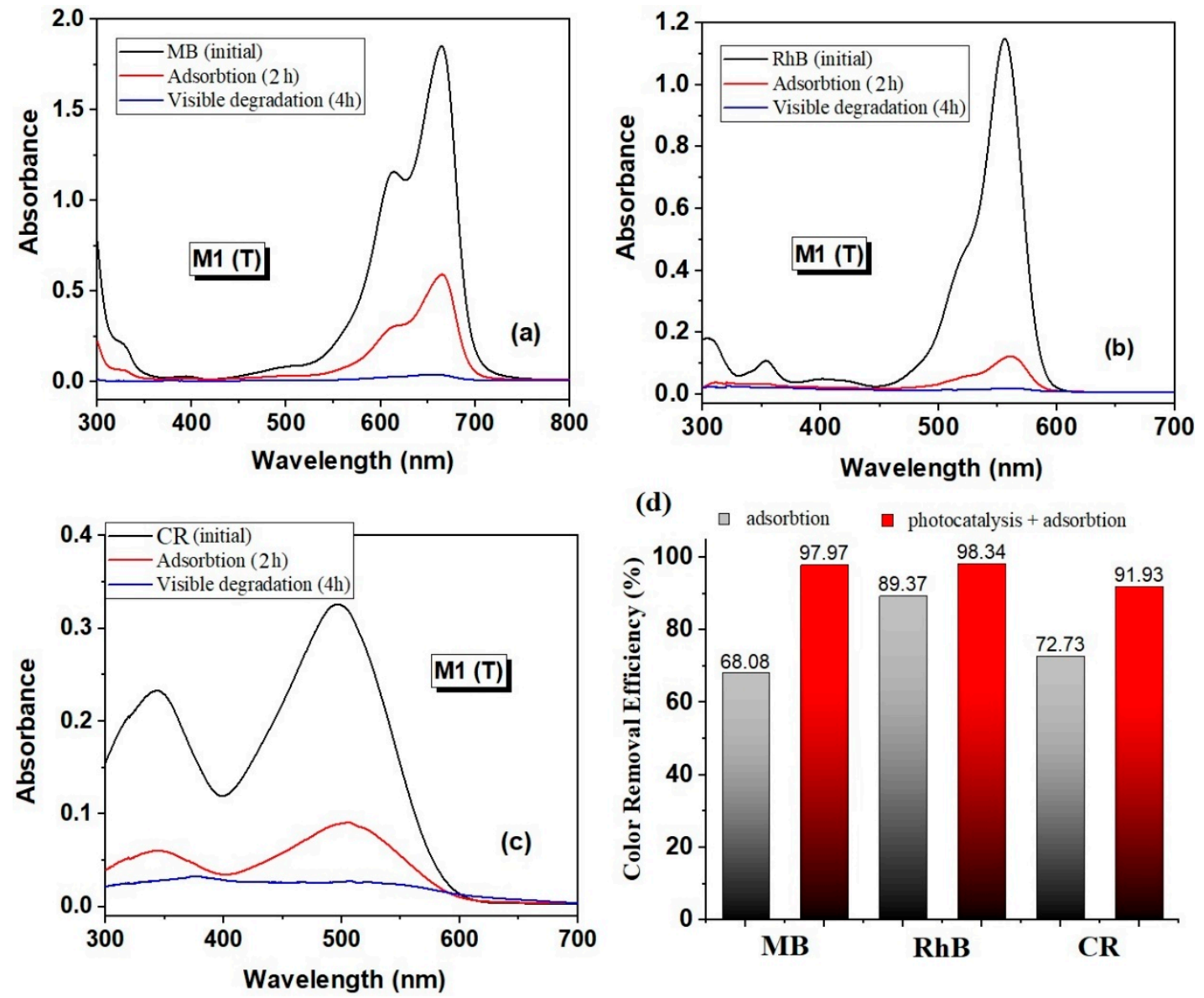

Figure 11. UV-Vis absorption spectra after adsorption $(2 \mathrm{~h})$ and visible light irradiation $(4 \mathrm{~h})$ in the presence of sample M1 (T) for degradation of MB ( $\left.C_{0}=10 \mathrm{mg} / \mathrm{L}\right)(\mathbf{a}) ; \operatorname{RhB}\left(C_{0}=5 \mathrm{mg} / \mathrm{L}\right)(\mathbf{b})$; Congo Red $(\mathrm{CR})\left(C_{0}=10 \mathrm{mg} / \mathrm{L}\right)(\mathbf{c})$, and color removal efficiency of all dyes degradation for sample M1 (T) (d).

Therefore, it can be stated that these materials could be employed as promising low-cost photocatalysts with impressive efficiency for potential applications in water purification and environmental protection. Under the given conditions-visible light irradiation at low power (a $100 \mathrm{~W}$ tungsten with a power of $102.74 \mathrm{~kJ} \cdot \mathrm{m}^{-2} \cdot \mathrm{h}^{-1}$ ), a moderate amount of catalyst $(0.5 \mathrm{~g} / \mathrm{L})$ and $4 \mathrm{~h}$ degradation process - the newly obtained materials present an outstanding response towards organic dyes degradation, with a removal efficiency of $91.93 \%, 97.97 \%$ and $98.34 \%$, depending on the type of dye.

Table 2 reveals the photocatalytic activities represented by the values of the reaction rate constant $k\left(\mathrm{~min}^{-1}\right)$ or degradation efficiency $(\%)$ for the degradation of different dyes in the presence of $\mathrm{ZnO} /$ carbon-based catalysts. As can be seen, good results were found for these materials based on different carbon nanostructures (reduced graphene oxide, graphene quantum dot, graphene oxide, carbon nanofibers, carbon) [15-18,44]. All authors reported an improvement in photocatalytic activity for these composite materials as compared to $\mathrm{ZnO}$. Instead, the materials analyzed in this study showed enhanced photocatalytic efficiency after $4 \mathrm{~h}$ under visible light irradiation at low intensity visible light in the degradation of all dyes (MB, RhB, and $\mathrm{CR})$. 
Table 2. Photocatalytic activities of carbon/ZnO nanostructured materials.

\begin{tabular}{|c|c|c|c|c|c|c|}
\hline Photocatalyst Type & $\begin{array}{c}\text { Type and } \\
\text { Concentration of Dye }\end{array}$ & $\begin{array}{c}\text { Amount of } \\
\text { Photocatalyst (g/L) }\end{array}$ & Light Source & $\begin{array}{c}\text { Reaction Rate } \\
\text { Constant } k\left(\mathrm{~min}^{-1}\right)\end{array}$ & $\eta(\%)$ & Ref. \\
\hline $\mathrm{ZnO} / \mathrm{RGO}$ & $\mathrm{MB}(10 \mathrm{mg} / \mathrm{L})$ & 1.25 & UV (100 W) & 0.0395 & - & [17] \\
\hline $\mathrm{ZnO} / \mathrm{GO}$ & Basic Fuchsin $(20 \mathrm{mg} / \mathrm{L})$ & 0.2 & UV & $0.00845(300 \mathrm{~min})$ & 92.5 & {$[44]$} \\
\hline $\mathrm{ZnO} /$ Graphene & $\mathrm{MO}\left(5 \times 10^{-5} \mathrm{M} / \mathrm{L}\right)$ & 0.08 & VIS $(300 \mathrm{~W})$ & 0.0116 & - & {$[16]$} \\
\hline \multirow{3}{*}{ Carbon/ZnO } & MB (10 mg/L) & \multirow{3}{*}{0.5} & \multirow{3}{*}{ Vis $(100 \mathrm{~W})$} & $0.002(240 \mathrm{~min})$ & 97.97 & \multirow{3}{*}{ This work } \\
\hline & $\mathrm{RhB}(5 \mathrm{mg} / \mathrm{L})$ & & & - & 98.34 & \\
\hline & CR $(10 \mathrm{mg} / \mathrm{L})$ & & & - & 91.93 & \\
\hline
\end{tabular}

According to the above results, a mechanism has been proposed to explain the improvement of the photocatalytic efficiency of the carbon/ZnO nanostructures as compared to pure $\mathrm{ZnO}$ (Figure 12).

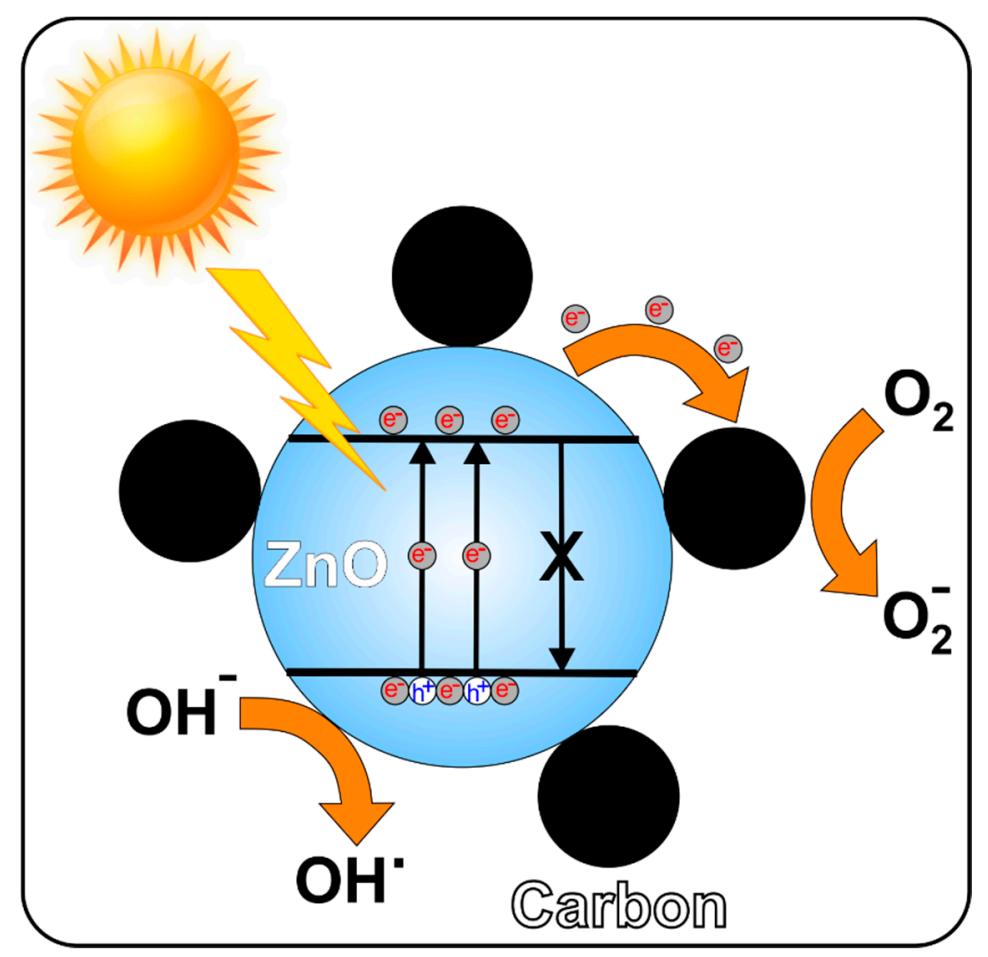

Figure 12. Proposed mechanisms of the photocatalysis of the carbon/ZnO nanostructures.

The degradation mechanism takes into account the cooperative or synergetic effects between the carbon generated during calcination and zinc oxide (Figure 12).

During photon excites, electron hole pairs are generated in the $\mathrm{ZnO}$ valence band. These excited electrons will move in the conduction band of $\mathrm{ZnO}$ and then diffuse toward the surface of the carbon particles. The holes excess in the valence band will migrate to the surface on $\mathrm{ZnO}$, where they react with water molecules or hydroxyl ions to generate active species of hydroxyl radicals $(\mathrm{OH})$. This method suggests that the photogenerated electrons and holes were effectively separated. Moreover, the good separation of the photogenerated electrons and holes in the carbon/ZnO nanostructures is supported by the photoluminescence investigations of $\mathrm{ZnO}$ and carbon/ZnO. According to Figure 7, carbon/ZnO nanostructures revealed weaker emission intensity compared to $\mathrm{ZnO}$. This aspect suggests that the recombination of the photogenerated charge carrier was highly inhibited in the carbon/ZnO nanostructures. The efficient charge separation could induce the increase of the charge carriers' lifetime by enhancing the efficiency of the interfacial charge transfer 
of the adsorbed substrates. This discussion is also supported by other studies regarding similar systems $[17,18]$.

\section{Conclusions}

Carbon/ZnO nanostructures were obtained in three stages: $\mathrm{CAB}$ microfiber mats were prepared by the electrospinning method, $\mathrm{ZnO}$ nanostructures were grown by dipping and hydrothermal methods, followed by thermal calcination at $600{ }^{\circ} \mathrm{C}$ in $\mathrm{N}_{2}$ atmosphere for $30 \mathrm{~min}$. XRD measurements of photocatalysts confirmed a hexagonal wurtzite crystalline structure of $\mathrm{ZnO}$, as well as the presence of carbon with (002) lattice planes. SEM measurements showed the formation of nanostructures with star-like and nanorod shapes. The $E_{\mathrm{g}}$ value decreased significantly for carbon/ZnO hybrid materials $(2.51 \mathrm{eV})$ as compared to $\mathrm{ZnO}$ nanostructures $(3.21 \mathrm{eV})$. The photocatalytic efficiency for degradation of Methylene Blue (MB), Rhodamine B (RhB) and Congo Red (CR) dyes under visible-light irradiation has been improved as compared to $\mathrm{ZnO}$. These new materials showed an improvement of the photocatalytic degradation efficiency for the $\mathrm{RhB}$ dye with approximately $80 \%$ as compared to the $\mathrm{ZnO}$ (control samples). The carbon/ZnO hybrid materials recorded a color removal efficiency (adsorption/photocatalytic process) between $91 \%$ and $98 \%$, depending on the type of dye. All the experiments were performed under friendly environmental conditions: visible light irradiation at low power and a moderate amount of catalyst $(0.5 \mathrm{~g} / \mathrm{L})$. Moreover, the value of the rate constant was found for this material to be $0.29 \times 10^{-2} \mathrm{~min}^{-1}$. Therefore, the prepared carbon/ZnO materials from easily accessible and low-cost materials together with their impressive performance place them among photocatalysts for practical applications in wastewater purification.

Author Contributions: Conceptualization; Data curation; Formal analysis; Investigation; Validation; Visualization, Validation, Writing-review and editing; P.P.; Conceptualization; Resources; Supervision; N.O.; Data curation, Supervision, A.R.; Resource, Visualization and Supervision A.A. All authors have read and agreed to the published version of the manuscript.

Funding: This work was supported by contract no. 18PFE/16.10.2018 funded by the Ministry of Research and Innovation within Program 1-Development of national research and development system, Subprogram 1.2-Institutional Performance-RDI excellence funding projects

Conflicts of Interest: The authors declare no conflict of interest.

\section{References}

1. Pascariu, P.; Homocianu, M. ZnO-based ceramic nanofibers: Preparation, properties and applications. Ceram. Int. 2019, 45, 11158-11173. [CrossRef]

2. Singh, K.; Kumar, P.; Srivastava, R. An overview of textile dyes and their removal techniques: Indian perspective. Pollut. Res. 2017, 36, 790-797.

3. Djurisic, A.B.; Chen, X.; Leung, Y.H.; Ng, A.M.C. ZnO nanostructures: Growth, properties and applications. J. Mater. Chem. 2012, 22, 6526-6535. [CrossRef]

4. Bolink, H.J.; Coronado, E.; Repetto, D.; Sessolo, M. Air stable hybrid organic-inorganic light emitting diodes using ZnO as the cathode. Appl. Phys. Lett. 2007, 91, 223501. [CrossRef]

5. Liao, Y.J.; Cheng, C.W.; Wu, B.H.; Wang, C.Y.; Chen, C.Y.; Gwo, S.; Chen, L.J. Low threshold room-temperature UV surface plasmon polariton lasers with $\mathrm{ZnO}$ nanowires on single-crystal aluminum films with $\mathrm{Al}_{2} \mathrm{O}_{3}$ interlayers. RSC Adv. 2019, 9, 13600-13607. [CrossRef]

6. Yoon, C.; Jeon, B.; Yoon, G. Development of $\mathrm{Al}$ foil-based sandwich-type $\mathrm{ZnO}$ piezoelectric nanogenerators. AIP Adv. 2020, 10, 045018. [CrossRef]

7. Kumar, R.; Umar, A.; Kumar, G.; Nalwa, H.S. Antimicrobial properties of ZnO nanomaterials: A review. Ceram. Int. 2017, 43, 3940-3961. [CrossRef]

8. Saha, J.K.; Bukke, R.N.; Mude, N.N.; Jang, J. Remarkable stability improvement of ZnO TFT with $\mathrm{Al}_{2} \mathrm{O}_{3}$ gate insulator by yttrium passivation with spray pyrolysis. Nanomaterials 2020, 10, 976. [CrossRef]

9. Gao, G.; Yu, L.; Vinu, A.; Shapter, J.G.; Batmunkh, M.; Shearer, C.J.; Yin, T.; Huang, P.; Cui, D. Synthesis of ultra-long hierarchical $\mathrm{ZnO}$ whiskers in a hydrothermal system for dye-sensitised solar cells. RSC Adv. 2016, 6, 109406-109413. [CrossRef] 
10. Pascariu, P.; Cojocaru, C.; Samoila, P.; Airinei, A.; Olaru, N.; Rusu, D.; Rosca, I.; Suchea, M. Photocatalytic and antimicrobial activity of electrospun ZnO:Ag nanostructures. J. Alloys Compd. 2020, 834, 155144. [CrossRef]

11. Pascariu, P.; Cojocaru, C.; Olaru, N.; Samoila, P.; Airinei, A.; Ignat, M.; Sacarescu, L.; Timpu, D. Novel rare earth (RE-La, Er, Sm) metal doped ZnO photocatalysts for degradation of Congo-Red dye: Synthesis, characterization and kinetic studies. J. Environ. Manag. 2019, 239, 225-234. [CrossRef] [PubMed]

12. Lang, J.; Wang, J.; Zhang, Q.; Li, X.; Han, Q.; Wei, M.; Sui, Y.; Wang, D.; Yang, J. Chemical precipitation synthesis and significant enhancement in photocatalytic activity of Ce-doped ZnO nanoparticles. Ceram. Int. 2016, 42, 14175-14181. [CrossRef]

13. Macías-Sánchez, J.J.; Hinojosa-Reyes, L.; Caballero-Quintero, A.; De la Cruz, W.; Ruiz-Ruiz, E.; Hernández-Ramírez, A.; Guzmán-Mar, J.L. Synthesis of nitrogen-doped ZnO by sol-gel method: Characterization and its application on visible photocatalytic degradation of 2,4-D and picloram herbicides. Photochem. Photobiol. Sci. 2015, 14, 536-542. [CrossRef]

14. Adnan, M.A.M.; Julkapli, N.M.; Hamid, S.B.A. Review on ZnO hybrid photocatalyst: Impact on photocatalytic activities of water pollutant degradation. Rev. Inorg. Chem. 2016, 36, 77-104.

15. Rahimi, K.; Yazdani, A.; Ahmadirad, M. Facile preparation of zinc oxide nanorods surrounded by graphene quantum dots both synthesized via separate pyrolysis procedures for photocatalyst application. Mat. Res. Bull. 2018, 98, 148-154. [CrossRef]

16. Xu, J.; Cui, Y.; Han, Y.; Hao, M.; Zhang, X. ZnO-graphene composites with high photocatalytic activities under visible light. RSC Adv. 2016, 6, 96778-96784. [CrossRef]

17. Xu, S.; Fu, L.; Pham, T.S.H.; Yu, A.; Han, F.; Chen, L. Preparation of ZnO flower/reduced grapheme oxide composite with enhanced photocatalytic performance under sunlight. Ceram. Int. 2015, 41, 4007-4013. [CrossRef]

18. Mu, J.; Shao, C.; Guo, Z.; Zhang, Z.; Zhang, M.; Zhang, P.; Chen, B.; Liu, Y. High Photocatalytic activity of ZnO-Carbon nanofiber heteroarchitectures. ACS Appl. Mater. Interfaces 2011, 3, 590-596. [CrossRef]

19. Batmunkh, M.; Biggs, M.J.; Shapter, J.G. Carbonaceous dye-sensitized solar cell photoelectrodes. Adv. Sci. 2015, 2, 1400025. [CrossRef]

20. Hu, C.; Lu, T.; Chen, F.; Zhang, R. A brief review of graphene-metal oxide composites synthesis and applications in photocatalysis. J. Chin. Adv. Mater. Soc. 2013, 1, 21-39. [CrossRef]

21. Concina, I.; Ibupoto, Z.H.; Vomiero, A. Semiconducting metal oxide nanostructures for water splitting and photovoltaics. Adv. Energy Mater. 2017, 7, 1700706. [CrossRef]

22. Shi, S.; Zhuang, X.; Cheng, B.; Wang, X. Solution blowing of ZnO nanoflake-encapsulated carbon nanofibers as electrodes for supercapacitors. J. Mater. Chem. A 2013, 1, 13779-13788. [CrossRef]

23. Samuel, E.; Joshi, B.; Kim, M.W.; Kim, Y.I.; Swihart, M.T.; Yoon, S.S. Hierarchical zeolitic imidazolate framework-derived manganese-doped zinc oxide decorated carbon nanofiber electrodes for high performance flexible supercapacitors. Chem. Eng. J. 2019, 371, 657-665. [CrossRef]

24. Zhang, L.; Aboagye, A.; Kelkar, A.; Lai, C.; Fong, H. A review: Carbon nanofibers from electrospun polyacrylonitrile and their applications. J. Mater. Sci. 2014, 49, 463-480. [CrossRef]

25. Lee, B.S.; Yu, W.R. Electrospun carbon nanofibers as a functional composite platform: A review of highly tunable microstructures and morphologies for versatile applications. Funct. Compos. Struct. 2020, 2, 012001. [CrossRef]

26. Pascariu, P.; Olaru, L.; Matricala, A.L.; Olaru, N. Photocatalytic activity of ZnO nanostructures grown on electrospun CAB ultrafine fibers. Appl. Surf. Sci. 2018, 455, 61-69. [CrossRef]

27. Pascariu, P.; Airinei, A.; Olaru, N.; Olaru, L.; Nica, V. Photocatalytic degradation of Rhodamine B dye using $\mathrm{ZnO}-\mathrm{SnO}_{2}$ electrospun ceramic nanofibers. Ceram. Int. 2016, 42, 6775-6781. [CrossRef]

28. Cojocaru, C.; Pascariu Dorneanu, P.; Airinei, A.; Olaru, N.; Samoila, P.; Rotaru, A. Design and evaluation of electrospun polysulfone fibers and polysulfone/ $\mathrm{NiFe}_{2} \mathrm{O}_{4}$ nanostructured composite as sorbents for oil spill cleanup. J. Taiwan Inst. Chem. Eng. 2017, 70, 267-281. [CrossRef]

29. Thamer, B.M.; El-Hamshary, H.; Al-Deyab, S.S.; El-Newehy, M.H. Functionalized electrospun carbon nanofibers for removal of cationic dye. Arab. J. Chem. 2019, 12, 747-759. [CrossRef]

30. Yun, S.I.; Kim, S.H.; Kim, D.W.; Kim, Y.A.; Kim, B.H. Facile preparation and capacitive properties of low-cost carbon nanofibers with $\mathrm{ZnO}$ derived from lignin and pitch as supercapacitor electrodes. Carbon 2019, 149, 637-645. [CrossRef] 
31. Samanta, P.K.; Bandyopadhyay, A.K. Chemical growth of hexagonal zinc oxide nanorods and their optical properties. Appl. Nanosci. 2012, 2, 111-117. [CrossRef]

32. Ge, M.Y.; Wu, H.P.; Niu, L.; Liu, J.F.; Chen, S.Y.; Shen, P.Y.; Zeng, Y.W.; Wang, Y.W.; Zhang, G.Q.; Jiang, J.Z. Nanostructured ZnO: From monodisperse nanoparticles to nanorods. J. Cryst. Growth 2007, 305, 162-166. [CrossRef]

33. Seow, Z.L.S.; Wong, A.S.W.; Thavasi, V.; Jose, R.; Ramakrishna, S.; Ho, G.W. Controlled synthesis and application of $\mathrm{ZnO}$ nanoparticles, nanorods and nanospheres in dye-sensitized solar cells. Nanotechnology 2009, 20, 045604. [CrossRef] [PubMed]

34. Lee, T.H.; Sue, H.J.; Cheng, X. Solid-state dye-sensitized solar cells based on ZnO nanoparticle and nanorod array hybrid photoanodes. Nanoscale Res. Lett. 2011, 6, 517. [CrossRef]

35. Anzlovar, A.; Orel, Z.C.; Kogej, K.; Zigon, M. Polyol-mediated synthesis of zinc oxide nanorods and nanocomposites with poly(methyl methacrylate). J. Nanomater. 2012, 2012, 760872. [CrossRef]

36. Hayashi, S.; Nakamori, N.; Kanamori, H. Generalized theory of average dielectric constant and its application to infrared absorption by ZnO small particles. J. Phys. Soc. Jpn. 1979, 46, 176-183. [CrossRef]

37. Wu, L.; Wu, Y.; Pan, X.; Kong, F. Synthesis of ZnO nanorod and the annealing effect on its photoluminescence property. Opt. Mater. 2006, 28, 418-422. [CrossRef]

38. Zhao, Q.; Xie, H.; Ning, H.; Liu, J.; Zhang, H.; Wang, L.; Wang, X.; Zhu, Y.; Li, S.; Wu, M. Intercalating petroleum asphalt into electrospun $\mathrm{ZnO} /$ Carbon nanofibers as enhanced free-standing anode for lithium-ion batteries. J. Alloys Compd. 2018, 737, 330-336. [CrossRef]

39. García-Díaz, I.; López, F.A.; Alguacil, F.J. Carbon nanofibers: A new adsorbent for copper removal from wastewater. Metals 2018, 8, 914. [CrossRef]

40. Morales, A.E.; Mora, E.S.; Pal, U. Use of diffuse reflectance spectroscopy for optical characterization of un-supported nanostructures. Rev. Mex. Fisica 2007, 53, 18-22.

41. Güler, Ö.; Güler, S.H.; Başgöz, Ö.; Albayrak, M.G.; Yahia, I.S. Synthesis and characterization of ZnO-reinforced with grapheme nanolayer nanocomposites: Electrical conductivity and optical band gap analysis. Mater. Res. Express 2019, 6, 095602. [CrossRef]

42. Tien, H.N.; Luan, V.H.; Ho, L.T.; Kho, N.T.; Hahn, S.H.; Chung, J.S.; Shin, E.W.; Hur, S.H. One-pot synthesis of a reduced graphene oxide-zinc oxide sphere composite and its use as a visible light photocatalyst. Chem. Eng. J. 2013, 229, 126-133. [CrossRef]

43. Pandy, P.; Kurchania, R.; Haque, F.Z. Structural, diffuse reflectance and photoluminescence study of cerium doped $\mathrm{ZnO}$ nanoparticles synthesized through simple sol-gel method. Optik 2015, 126, 3310-3315. [CrossRef]

44. Durmus, Z.; Kurt, B.Z.; Durmus, A. Synthesis and characterization of Graphene Oxide/Zinc Oxide (GO/ZnO) nanocomposite and its utilization for photocatalytic degradation of basic fuchsin dye. ChemistrySelect 2019, 4, 271-278. [CrossRef]

(C) 2020 by the authors. Licensee MDPI, Basel, Switzerland. This article is an open access article distributed under the terms and conditions of the Creative Commons Attribution (CC BY) license (http://creativecommons.org/licenses/by/4.0/). 